\title{
The Incidence of Aflatoxin M1 in Milk Produced in a Regional Surveillance System Between 2013 and 2017
}

\author{
Alina FĂT ${ }^{1 *}$, Sorin Daniel DAN ${ }^{1}$, Alexandra TĂBĂRAN ${ }^{1}$, Oana REGET $^{1}$, Daiana MIKLE ${ }^{2}$, Romolica \\ MIHAIU $^{3}$, Marian MIHAIU ${ }^{1}$ \\ ${ }^{1}$ Department of Animal Production and Food Safety, University of Agricultural Sciences and Veterinary \\ Medicine, Faculty of Veterinary Medicine, 3-5 Mănăștur Street, Cluj Napoca, Romania \\ ${ }^{2}$ Department of Anatomic pathology, University of Agricultural Sciences and Veterinary Medicine, \\ 3 Babeș-Bolyai University, Faculty of Economics and Business Administration, Management Department, \\ 58-60 Teodor Mihali Street, Cluj-Napoca, Romania \\ * corresponding author: fat.alinaioana@yahoo.com
}

Babeș-Bolyai University, Faculty of Economics and Business Administration, Management Department, 58-60 Teodor Mihali Street, Cluj-Napoca, Romania Bulletin UASVM Veterinary Medicine 75(1)/2018

Print ISSN 1843-5270; Electronic ISSN 1843-5378

doi:10.15835/buasvmcn-vm:006417

\begin{abstract}
Aflatoxins are toxic metabolites, generally produced by Aspergillus flavus, A. parasiticus and A. Nomius. They can have immunosuppressive, mutagenic, teratogenic and carcinogenic effects, especially on the liver. The purpose of this study was to evaluate the frequency of AFM1 contamination in milk in an established surveillance area of Romania, during 2013-2017 period. The material was represented by 150 raw milk samples obtained from milk collecting units and breeding units in Cluj county. The samples were analyzed by ELISA method. Measurable levels of AFM1 were present in $28 \%$ of the milk samples examined. The level of AFM1 in the positive samples ranged between 0,010 and $0,089 \mu \mathrm{g} / \mathrm{kg}$. Of the total samples, only two were found non-compliant with the EU regulatory limit $(0.05 \mu \mathrm{g} / \mathrm{kg})$. All the positive samples were detected in 2013. In the 2014-2017 period, the level of aflatoxin M1 in milk was undetectable. The contamination risk of AFM1 in milk may increase with feeds being stored in improper conditions of humidity and temperature. This risk can be significantly reduced by using aflatoxin uncontaminated feeds.
\end{abstract}

Keywords: Aflatoxin M1, ELISA, incidence, raw milk

\section{Introduction}

Mycotoxins are natural chemicals produced by certain fungi which occur as contaminnts of some food crops, either in the field or during postharvest storage. The majority of the mycotoxins are produced by three fungal genera: Aspergillus, Penicillium and Fusarium. They contaminate a vast array of food and agricultural commodities (Schmidt-Heydt and Geisen, 2007; Hamid, 2011).

Aspergillus species are capable of growing on a variety of substrates and under a variety of environmental conditions. Survives on many organic nutrient sources like plant debris, tree leaves, decaying wood, animal fodder, cotton, compost piles, dead insects and animal carcasses or stored grains. Aflatoxins often occur in crops in the field prior to harvest. Post harvest contamination can occur if crop drying is delayed and during storage of the crop if water is allowed to exceed critical values for the mould growth. Insect or rodent infestations facilitate mould invasion of some stored commodities (Rajeev et al., 2010).

Therefore, most foods are susceptible to aflatoxigenic fungi at some stage of production, processing, transportation, and storage. The rate and level of contamination are dependent on temperature, humidity and soil and storage conditions (Rajeev et al., 2010). 
The production of aflatoxins is influenced by physical, chemical and biological factors. The physical factors include temperature and moisture. The chemical factors include the composition of the air and the nature of the substrate. Biological factors are those associated with the host species (Hesseltine, 1983).

Aflatoxins are produced by three species of Aspergillus-A. flavus, A. parasiticus, and the rare A. nomius - which contaminate plants and plant products. A. flavus produces only B aflatoxins, while the other two species produce both $B$ and $G$ aflatoxins. Being intensely fluorescent in ultraviolet light the aflatoxins are designated by letters B1, B2, G1 and G2 representing their blue and green fluorescence in UV light. Aflatoxins M1 and M2 are the hydroxylated metabolites of aflatoxin B1 and B2 and may be found in milk products obtained from livestock that have ingested contaminated feed (Pei et al., 2009; Montagna et al., 2008).

Fungal toxins produce a wide range of clinical effects in animals. The economic impact of reduced productivity, increased incidence of disease because of immune suppression, subtle but chronic damage to vital organs and tissues, and interference with reproductive capacity is many times greater than that of acute livestock death (Creppy, 2002).

Aflatoxins cause liver damage, decreased milk production, and suppression of immunity in animals consuming low dietary concentrations. Nursing animals may be affected by exposure to aflatoxin metabolites secreted in the milk. While the young of a species are most susceptible to aflatoxins, all ages can be affected. Clinical signs include gastrointestinal dysfunction, reduced reproductive function, decreased feed consumption and efficiency, anemia, and jaundice (Creppy, 2002).

Upon entering the body it may cause damage to the DNA ultimately leading to mutagenic and carcinogenic effects, whereas in the case of aflatoxicosis, liver is the main target organ (Fung and Clark, 2004). The International Agency for Research on Cancer has classified AFM1 as a group 2B carcinogen (possibly carcinogenic to humans) (Pei et al., 2009, Tsakiris et al. 2013).

Aflatoxin B1 (AFB1) is the most toxic metabolite, demonstrating teratogenic, mutagenic and carcinogenic effects (Stagos et al., 2012). AFM1 is the main thermo-resistant hydroxylated derivative of AFB1formed in liver by means of P450 cytochrome enzymes. It is then excreted in the milk and may subsequently contaminate other dairy products such as cheese and yoghurt (Aziz, 2010; Aycicek et al., 2005; Fallah et al., 2009).

The AFM1 derivative can be detected in milk within 12-24 h after the first intake of AFB1, while its concentration decreases to an undetectable level $72 \mathrm{~h}$ after the initial intake is stopped (Fallah, 2010). AFM1 is very resistant to thermal treatments such as pasteurization and sterilization during dietary milk production (Galvano et al., 1996; Tsakiris et al. 2013, Mahdiyeh et al., 2013).

Aflatoxins are crystalline substances, freely soluble in moderately polar solvents such as chloroform, methanol and dimethyl sulfoxide, and dissolve in water to the extent of $10-20 \mathrm{mg} /$ litre. They fluoresce under UV radiation. Crystalline aflatoxins are extremely stable in the absence of light and particularly UV radiation, even at temperatures in excess of $100{ }^{\circ} \mathrm{C}$ (Watson, 1998).

Romanian legislation has been adapted to EU legislation and the maximum admitted level for AFM1 in milk and milk products is $0.05 \mu \mathrm{g} / \mathrm{kg}$. (Commision Regulation).

The purpose of this study was to evaluate the frequency of AFM1 contamination in milk in an established surveillance area of Romania, during 2013-2017 period, using the ELISA method.

\section{Materials and methods Sampling}

A total of 150 samples of raw milk were obtained from milk collecting units and breeding units during 2013 to 2017 from Cluj county. All the samples of milk were prepared using the method outlined in the ELISA kits and according to official method specified in ELISASystem Aflatoxin M1. (RIDAScreen aflatoxin M1).

\section{Reagents}

A set for the determination of aflatoxin M1 included a 96-well plate coated with antibodies to aflatoxin M1; standard solutions of alfatoxin M1 in milk with concentrations: $0,5,10,20,40$, and $80 \mathrm{ng} / \mathrm{dm} 3$, a solution of peroxidase-aflatoxin M1 conjugate; a substrate containing urea peroxide; a chromogen containing tetramethylbenzidine; sulphuric acid (1 $\mathrm{mol} / \mathrm{dm} 3)$ as a reagent for process termination; a buffer for diluting the solutions of examined and standard samples; a buffer for diluting the conjugate. 


\section{Sample preparation}

The milk sample was centrifuged for degreasing, 10 minutes at $3500 \mathrm{~g} / 10^{\circ} \mathrm{C}$, if the centrifuge is not cooled, the milk sample is cooled to $2-8^{\circ} \mathrm{C}$ before centrifugation. The fatty layer was removed and $100 \mu \mathrm{l}$ of the defatted milk was applied directly in the ELISA kit for AFM1 determination.

\section{Analysis of AFM1 in samples by ELISA}

Before starting the test, the reagents were brought up to room temperature. The AFM1 standards and test samples (100 $\mu \mathrm{l}$ per well) in duplicate were added to the wells of a micro-titer plate pre-coated with antibodies for AFM1 and incubated at room temperature in dark for $30 \mathrm{~min}$. Liquid was discarded by capsizing the plate and each well was washed 2 times with $250 \mu$ l of wash buffer supplied in the kit. After the washing step, $100 \mu$ l of peroxidase conjugate was added to the wells and plate was incubated again for $15 \mathrm{~min}$ at room temperature in dark. The washing procedure was repeted for two times. After the washing step, the unbound conjugate was removed during washing. Subsequently, $100 \mu \mathrm{l}$ each substrate (urea peroxide) and chromogen (tetramethylbenzidine) were added to the wells and incubated for $15 \mathrm{~min}$ in dark. Finally, $100 \mu \mathrm{l}$ of stop solution were added to each well. The optical absorbance of each well was read at $450 \mathrm{~nm}$ with ELISA plate reader. Absorbance percentages were taken to the calibration curve performed with standards at different concentrations.

\section{Statistical analysis}

The results were analyzed by one-way analysis of variance (ANOVA) and considered statistically difference at 95\% confidence levels.

\section{Results and discussions}

A total of 150 samples of raw milk were analyzed in the period 2013 - 2017, to determine the incidence of the aflatoxin M1 contamination in this samples. During this period, positive samples were detected only in 2013. The material used in 2013 was represented by 61 raw milk samples analyzed and tested by immuno-enzymatic ELISA method. Of the total samples, 22 were obtained from milk collecting units and 39 from breeding units. The study shows that $60.65 \%$ of the samples analyzed in 2013 were positive.

Surprisingly, in the breeding units with less than 100 individuals, aflatoxin M1 was identified in a proportion of $71.4 \%$. None of the positive samples exceeded the limit of $0.05 \mu \mathrm{g} / \mathrm{kg}$, which is the maximum allowed (Figure 1).

The samples gathered from collecting centers were positive in $68 \%$, and 2 samples showed values that exceeded the value stated by the current legislation. The minimum and maximum contamination level of AFM1 was found to be 0,010 and $0,089 \mu \mathrm{g} / \mathrm{kg}$, respectively.

Maximum admissible value $-0.05 \mu \mathrm{g} / \mathrm{kg}$

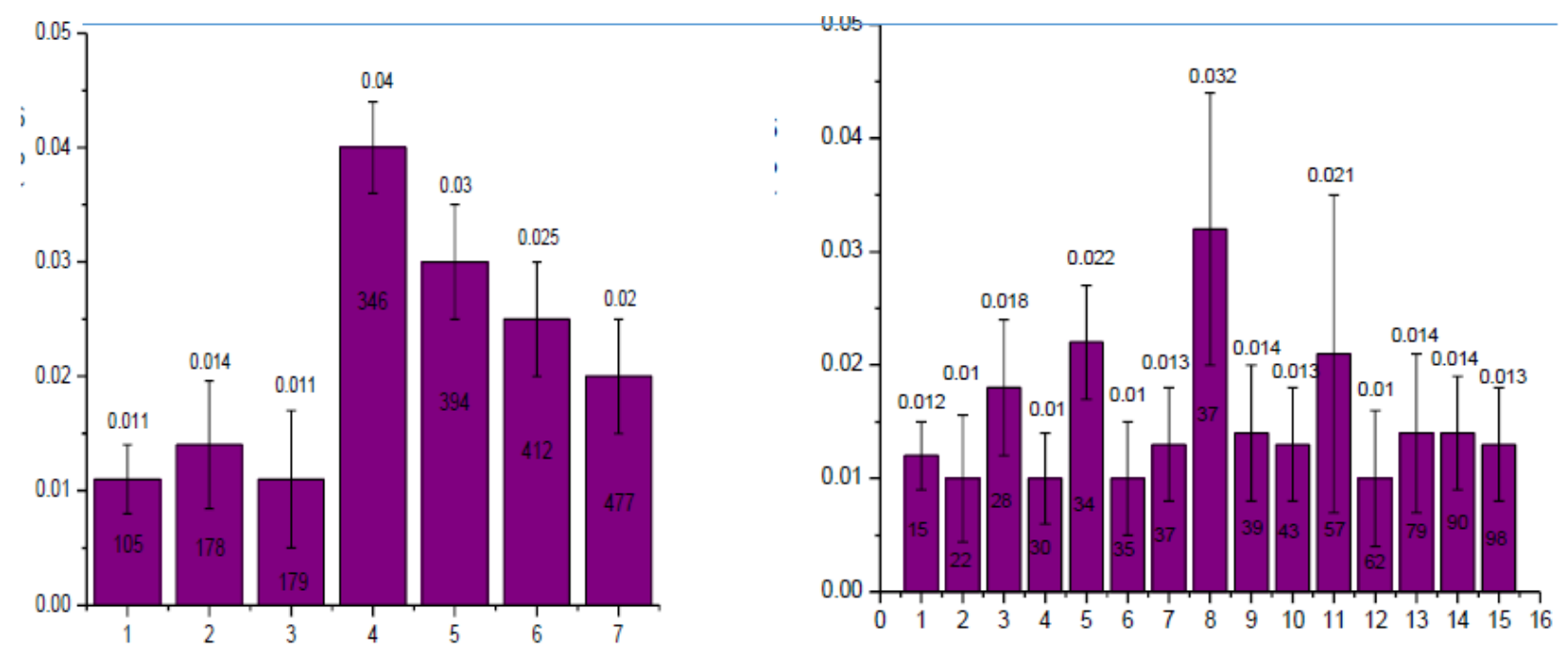

Figure 1. Aflatoxin M1 concentration in bovine breeding units 


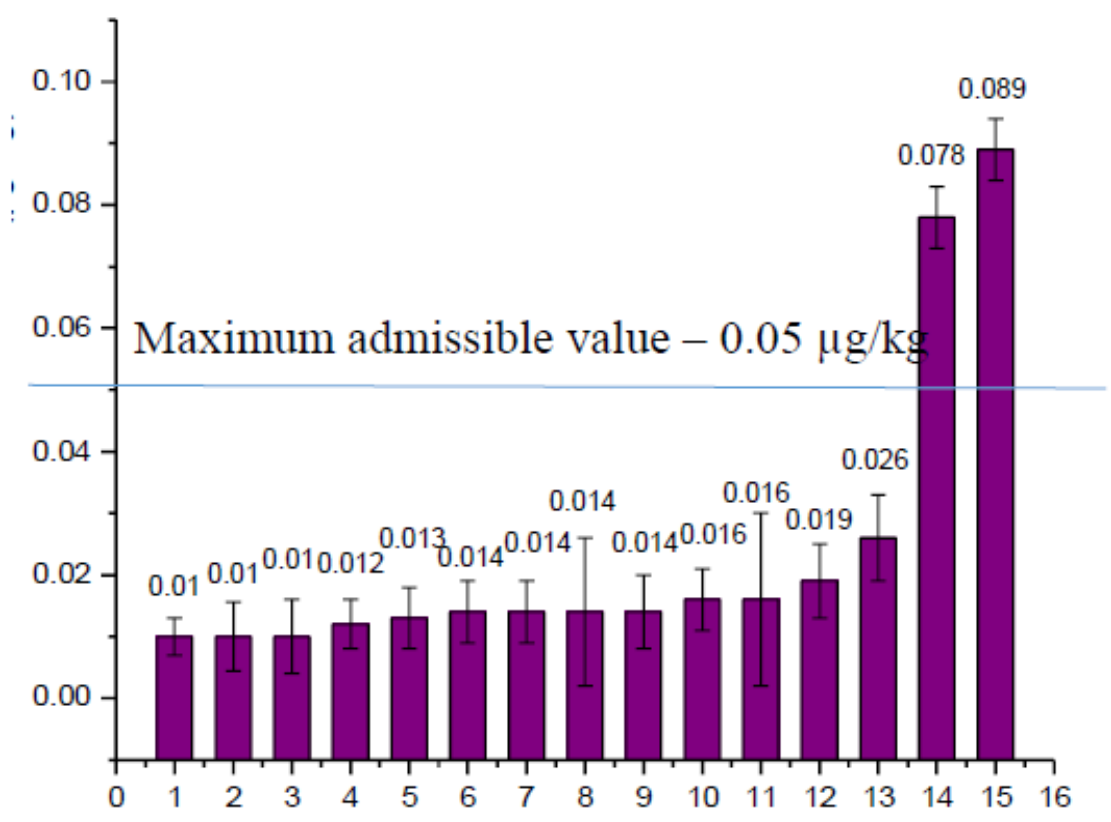

Figure 2. The concentration of aflatoxin M1 in milk collecting units

Following the high incidence of aflatoxin M1 detected in milk in 2013, rigorous controls by the veterinary authorities took place. Also, the producers have been alerted to the potential risk posed by milk contamination with aflatoxin for the consumer health. These measures led to a decrease in the level of aflatoxin M1 to undetectable values over the period 2014-2017. The control of contaminants in food of animal origin in Romania performs on the basis of the specific program developed by The National Sanitary Veterinary and Food Safety Authority, in which is specified the number of samples for the each county, analytical laboratories and the time period during which samples will be taken.

Food safety and foodborne diseases constitute a growing public health problem (WHO, 2009). Thus, great attention must be given to food control especially mycotoxins investigation in food due to their deleterious effect on human health. Mycotoxins are metabolites of fungi capable of having acute toxic, carcinogenic, mutagenic, teratogenic, immunotoxic, and oestrogenic effects in man and animals (van Egmond et al., 2007).

Mycotoxin compounds are extremely stable and also dangerous in minute quantities. A few parts per billion are of concern. Once formed, they cannot be removed from the commodity. Milk, as a liquid, is a highly variable product that rapidly loses its quality and spoils if not to be treated. Since milk may be processed in numerous ways, the effects of storage and processing on stability and distribution of AFM1 are of great concern. Many researchers from different countries have carried out studies about the incidence of AFM1 in milk; many authors showed that seasonal effect influences concentration of aflatoxin M1. They reported higher concentration of AFM1 in cold seasons as compared to hot seasons, the reason being in winters mostly milking animals are fed with compound feeds and thus concentration of AFB1 increases which in turn enhances AFM1 concentration in milk (Applebaum et al., 1982; Blanco et al., 1988b; Hussain and Anwar, 2008; Tajkarimi et al. 2008; Fallah, 2010; Bilandzic et al., 2010; Azizollahi et al., 2012; Aiad and Abo ElMakarem, 2013).

As aflatoxin M1 has toxicological properties comparable to those of aflatoxin B1, albeit a lower carcinogenic potency, maximum levels for aflatoxin M1 in Romania have been set for consumable milk at $0.05 \mu \mathrm{g} / \mathrm{kg}$, and $0.025 \mu \mathrm{g} / \mathrm{kg}$ for infant formulae, respectively.

Considering the health risks associated with AFM1, many countries have established legal limits for maximum residue level (MRL) of AFM1 in milk. These limits are not universal to all countries. The EU countries, some countries 
in Africa, Asia and Latin America generally apply a maximum level of $0.05 \mu \mathrm{g}$ aflatoxin M1/kg milk. In contrast, the USA as well as some European and several Asian countries accept a maximum level of $0.5 \mu \mathrm{g} / \mathrm{kg}$ aflatoxin M1 in milk. The $0.5 \mu \mathrm{g} / \mathrm{kg}$ limit for aflatoxin M1 has also been adopted by the Codex Alimentarius (Codex Alimentarius, 2001). Thus, the maximum permitted level of aflatoxin M1 in milk in the EU is among the lowest in the world (EFSA, 2004).

Between 2004-2008, in the West region of Romania over 1322 samples of raw milk (815) and milk products (consumption milk - 147, powder milk - 70, yogurts - 172, cheeses - 58, butter - 60) were analysed. From the total samples of raw milk, $26.2 \%$ were over the maximum admitted level of $0.05 \mu \mathrm{g} / \mathrm{kg}(0.05 \mathrm{ppb})$. No positive samples were found in yogurt samples, cheeses and butter samples. For powder milk, the level of aflatoxin detected was lower that the maximum level admitted (Damiescu and Trif, 2009). Another study was developed in the Braşov County, between 2005-2006 to determine the aflatoxin's content variation - in the fodder and foodstuff from samples that have been harvested from farms, production units and food markets. In 2005 the alimentary stuff represented $95 \%$ of the tested products, while the animal feed represented only $5 \%$. In 2006 the alimentary stuff represented $76.67 \%$ of the tested products, while the animal feed represented only 33. $33 \%$. None of the samples presented values above the allowed present limits (Potrovita et al., 2007).

A study in dairy products in Southern Italy, in 2008 revealed the presence of AFM1 in 16.6\% of the cheeses tested: $31.3 \%$ of these were sheepgoat cheeses, $27.2 \%$ cow, $16.7 \%$ goat and $12.8 \%$ sheep cheeses, with no significant difference. The samples of buffalo milk cheese were consistently negative (Montagna et al., 2008; Yapar et al., 2008). Another cumulative datas from surveys conducted throughout northwestern Italy between 2012 and 2014 rate a contamination with AFM1 in a porcent of $2.2 \%$ but less than $1 \%$ of milk samples of the total number were noncompliant with the EU limit. Previous studies reported a contamination rate of $14 \%$ in milk samples from southern Italy, though the AFM1 level was never above the permitted EU limit (range 0 to $40 \mathrm{ppt}$ ) (Grasso et al., 2001). The low rates found for northwest Italy can be explained as a result of the implementation of own-check analyses. Mandatory for dairy cow milk producers, this system entails daily analyses of milk samples during high-risk periods to alert for the presence of AFM1 when detected at concentrations above the permitted level. If an alert has been signaled, the farmer must withdraw the products and suspend delivering milk to market (Bellio et al., 2016). A study in processed milk was developed in Serbia, between 20152016 to determine the aflatoxin content seasonal variation. In 2015, the presence of AFM1 was revealed in $77.8 \%$ of samples and in a procent of $98.4 \%$ in samples collected in 2016. The highest AFM1 levels were measured in October 2015 $(0.278 \mu \mathrm{g} / \mathrm{L})$ and September $2016(0.279 \mu \mathrm{g} / \mathrm{L})$ (Milievi et al., 2017).

During 2015, another study was conducted in Serbia, to compare the occurrence of AFM1 in raw milk and dairy products and also to determine whether there were some differences in AFM1 level among seasons. The results revealed that the AFM1 level exceeded the European Union maximum permitted level in $29.3 \%$ of raw milk and $4.2 \%$ of milk product samples. The highest level of AFM1 in raw milk was found during the autumn season, while during the rest of the 2015, it was significantly lower (Miocinovic et al,. 2016). In different regions of Croatia during spring and autumn 2016 were collected and analysed samples of raw cow, goat and sheep milk. Aflatoxin M1 concentrations were measured in the following ranges (ng/kg): cow milk 0.93-85.4; goat milk 2.0-18.6 and sheep milk 2.27-11.2. The maximum permitted level of aflatoxin M1 was exceeded in two cow milk samples in spring and 10 cow milk samples in autumn. The results from the exposure assessment showed no risk for consumers in 2016 (Bilandžić et al., 2017).

In Jordanian market, between 2014-2015 a total of 175 different products samples were analysed. All tested samples were contaminated with various levels of AFM1 ranging from 9.71 to $288.68 \mathrm{ng} / \mathrm{kg}$. The concentration of AFM 1 in $66 \%$ of fresh milk samples was higher than the maximum tolerance limit accepted by the European Union (50 ng/kg) and 23\% higher than the maximum tolerance limit accepted by the US $(500 \mathrm{ng} / \mathrm{kg})$. Percentages of contaminated raw cow, sheep, goat and camel milk exceeding the European tolerance limit were $60,85,75$ and $0 \%$, respectively. Of AFM1 contaminated pasteurised cow milk samples, $12 \%$ 
exceeded the European tolerance limit with a range of contamination between 14.60 and 216.78 $\mathrm{ng} / \mathrm{kg}$. For infant formula samples, the average concentration of AFM1 was $120.26 \mathrm{ng} / \mathrm{kg}$ (range from 16.55 to $288.68 \mathrm{ng} / \mathrm{kg}$ ), the concentration of AFM1 in $85 \%$ of infant formula samples was higher than the maximum tolerance limit accepted by the European Union and the US (25 ng/ $\mathrm{kg}$ ) (Sharaf, 2016).

\section{Conclusion}

The present study reveals that the contamination risk of AFM1 in milk may increase with feeds being stored in improper conditions of humidity and temperature. This risk can be significantly reduced by using aflatoxin uncontaminated feeds. In addition, it is important that feeds be frequently analysed for aflatoxins before feeding. The best protection against mycotoxins is monitoring for their presence in feed and foods, testing all along the pathway from initial harvest of grains to the finished product.

Also, it is important to reduce the occurrence of toxins (AFB1) in feedstuff and take prophylactic measures to prevent factors enhancing toxin production. These factors include environmental temperature, humidity, and moisture content of the feed as well as $\mathrm{pH}$ and mechanical damage to the grain affecting mould production.

Acknowledgments. This research did not receive any specific grant from funding agencies in the public, commercial, or not-for-profit sectors.

\section{References}

1. Aiad AS, Abo El-Makarem H (2013). Aflatoxin M1 levels in milk and some dairy products in Alexandria city. Assiut Vet Med. J., 59 (139): 93-98.

2. Applebaum RS, Brackett RE, Wiseman DW, Marth EH (1982). Aflatoxins: toxicity to dairy cattle and occurrence in milk and milk products. Journal of Food Protection, 45:752-777.

3. Aycicek H, Aksoy A, Saygi S (2005). Determination of aflatoxin levels in some dairy and food products which consumed in Ankara, Turkey. Food Control, 16:263-266 .

4. Aziz AF (2010). Aflatoxin M1 contamination in dairy products marketed in Iran during winter and summer. Food Control, 2: 1478-1481.

5. Azizollahi AM, Issazadeh R, Kazemi Darsanaki M, Laleh R, Amini A (2012). Determination of Aflatoxin M1 Levels in White Cheese Samples by ELISA in Gilan Province, Iran. Global Veterinaria, 8 (7): 707- 710.
6. Bellio A, Bianchi DM, Gramaglia M, Loria A, Nucera D, Gallina S, Gili M, Decastelli L (2016). Aflatoxin M1 in Cow's Milk: Method Validation for Milk Sampled in Northern Italy. Toxins (Basel), 8(3): 57.

7. Bilandžić N, Varenina I, Kolanović B S, Božić LuburićĐ, Varga I, Želježić B, Cvetnić L, Benić M, Tanković S, Cvetnić Ž (2017). Occurrence of aflatoxin M1 in raw cow, goat and sheep milk during spring and autumn in Croatia during 2016, Toxin Reviews, 36(4):290-296.

8. Bilandzic N, Varenina I, Solomun B (2010). Aflatoxin M1 in raw milk in Croatia. Food Control, 21: (1279-1281)

9. Blanco JL, Dominguezs L, Gomez-Lucia E, Garayzabal JFF, Gracia JA, Suarez G (1988b). Presence of aflatoxin M1 in commercial ultra-high temperature treated milk. Applied Environmental Microbiology, 56:1622-1623.

10. Codex Alimentarius Commissions, 2001. Commission Submitted on the Draft Maximum Level for Aflatoxin M1 in Milk. Codex Committee on Food Additives and Contamination 33rd Sessions, Hauge, The Netherlands.

11. Creppy EE (2002). Update of survey, regulation and toxic effects of mycotoxins in Europe. Toxicology Letters, 127:19-28.

12. Damiescu L, Trif A (2009). The incidence of Aflatoxin M1 in milk and dairy products in the west counties of Romania in the period 2004-2008. Scientific works, C series LV (2), ISSN 1222-5304

13. EFSA Journal (2004) 39, 1-27 - Opinion of the Scientific Panel on Contaminants in the Food Chain on a request from the Commission related to Aflatoxin B1 as undesirable substance in animal feed, http://www.efsa.eu.int

14. Fallah AA (2010). Aflatoxin M1 contamination in dairy products marketed in Iran during winter and summer. Food Control, 21:1478-1481.

15. Fallah AA, Jafari T, Fallah A, Rahnama M (2009). Determination of aflatoxin Ml levels in Iranian white and cream cheese. Food and Chemical Toxicology, 47:18721875.

16. Fung F, Clark RF (2004). Health Effects of mycotoxins: a toxicological overview. J. Toxicol. Clin. Toxicol., 42:217234.

17. Galvano F, Galorafo V, Galvano G (1996). Occurrence and stability of aflatoxin M1 in milk and milk products: a worldwide review. J. Food Prot., 59:1079-1090.

18. Grasso L, Scarano G, Salzillo A, Serpe L (2001). Studio sulla presenza di aflatossina M1 nel latte e nei suoi derivati provenienti dalle regioni Campania e Calabria. La Rivista di scienza dell'alimentazione, 30:29-34.

19. Hamid M (2011). A Review of Aflatoxin M1, Milk, and Milk Products, Aflatoxins - Biochemistry and Molecular Biology, Dr. Ramon G. Guevara-Gonzalez (Ed.), ISBN: 978953-307-395- 8, InTech, Available from: http://www. intechopen.com/books/aflatoxins-biochemistry-andmolecularbiology/a-review-of-aflatoxin-m1-milk-andmilk-products

20. Hesseltine CW (1983). Introduction, definition and history of mycotoxins of importance to animal production. In: Interactions of mycotoxins in animal production. National Academy of Science, Washington, DC. 
21. Hussain I, Anwar J (2008). A study on contamination of aflatoxin M1 in raw milk in the Punjab province of Pakistan. Food Control, 19:293-295.

22. Mahdiyeh LR, Reza Kazemi Darsanaki, Mahya Mohammadi, Masoud Hassani Kolavani, Khosro Issazadeh and Morteza Azizollahi Aliabadi (2013). Determination of Aflatoxin M1 Levels in Raw Milk Samples in Gilan, Iran. Advanced Studies in Biology, 5(4):151 - 156.

23. Milievi D et al (2017). IOP Conf. Ser.: Earth Environ. Sci. 85 012040, DOI: 10.1088/1755-1315/85/1/012040

24. Miocinovic J, Keskic T, Miloradovic Z, Kos A, Tomasevic I, Pudja P (2016). The aflatoxin M1 crisis in Serbian dairy sector: the year after. Food Addit Contam Part B Surveill. , 10(1):1-4.

25. Montagna MT, Napoli C, De Giglio O, Iatta R, Barbuti G (2008). Occurrence of Aflatoxin M1 in Dairy Products in Southern Italy. Int. J. Mol. Sci., 9:2614-2621

26. Pei SC, Zhangm YY, Eremin SA, Lee WJ (2009). Detection of aflatoxin M1 in milk products from China by ELISA using monoclonal antibodies. Food Control, 20:2080-2085.

27. Potrovita M, Roman M, Plotogea A (2007). The Variation of Aflatoxine in Few Fodder and Food Products in Brasov County. Journal of Agroalimentary Processes and Technologies, 13(2):331-338.

28. Rajeev Bhat, Ravishankar V. Rai, Karim AA (2010). Mycotoxins in Food and Feed: Present Status and Future Concerns. Vol. 9, 2010 - Comprehensive Reviews In Food Science And Food Safety: 57-81

29. RIDASCREEN $®$ Aflatoxin M1 Art. No. R1121 - Enzyme immunoassay for the quantitative determination of aflatoxin M1
30. Schmidt-Heydt M, Geisen R (2007). A microarray for monitoring the production of mycotoxins in food. International Journal of Food Microbiology, 117(2):131140.

31. Sharaf SO (2016). Aflatoxin M1 levels in raw milk, pasteurised milk and infant formula. Department of Nutrition and Food Processing, Al-Balqa Applied University, Salt, Jordan. Italian Journal of Food Safety, 5:5788.

32. Stagos D, Amoutzias G, Matakos A, Spyrou A, Tsatsakis A, Kouretas D (2012). Chemoprevention of liver cáncer by plant polyphenols. Food Chem. Toxicol., 50:2155-2170.

33. Tsakiris IN, Tzatzarakis MN, Alegakis AK, Vlachou MI, Renieri EA, Tsatsakis AM (2013). Risk assessment scenarios of children's exposure to aflatoxin M1 residues in different milk types from the Greek market. Food Chem. Toxicol., http://dx.doi.org/10.1016/j.fct.2013.02.024

34. van Egmond HP, Schothorst RC, Jonker MA (2007). Regulations relating to mycotoxins in food: Perspectives in a global and European context. Anal Bioanal Chem. 389:147-157.

35. Watson DH (1998). Natural Toxicants in Food. Sheffield Academic Press - CRC Press.

36. WHO (2009). Food Safety. Available at http://apps.who. int/gb/ebwha/pdf_files/A62/A62_21-fr.pdf

37. Yapar K, Elmali M, Kart A, Yaman H (2008). Aflatoxin M1 levels in different type of cheese products produced in Turkey. Medycyna Wet., 64:53-55. 